\title{
Motivational Issues for Teachers in Higher Education: A Critical Case of IUB
}

\author{
Muhammad Imran Rasheed (Corresponding Author) \\ Department of Management Sciences, The Islamia University of Bahawalpur, Pakistan \\ E-mail: emranrsheed@gmail.com
}

Hassan Danial Aslam

Department of Management Sciences, The Islamia University of Bahawalpur, Pakistan

E-mail: h_danial_aslam@live.com

Shakeel Sarwar

Department of Management Sciences, The Islamia University of Bahawalpur, Pakistan

E-mail: ch.ssarwar@yahoo.com

\begin{abstract}
Purpose -The aim of this research is to explore various issues of motivation for the teachers in higher education institutions.

Design / Methodology- This is an exploratory research where survey has been conducted in a well known public sector university; primary data has been collected through questionnaire and in depth face to face interviews.

Findings- Findings have shown that although compensation and benefits are important factors in competitive market environment but some intangibles motivators like job design, work environment, feedback, recognition and empowerment or decision making participation are also the potential factors for motivating teachers in higher education.

Contribution- This study can play a vital role in compelling the higher education authorities to ponder over the motivational issues of teachers in universities. The case studied in this research can prove to be an effectual case for other world wide universities where teachers are facing alike issues.
\end{abstract}

Keywords: Human Resource Management, Motivation, Retention, Higher education, Teachers 


\section{Introduction}

Every organization has three types of general resources that are physical, financial and human. Most critical one is no doubt the human resource of an organization. These are the humans who can accelerate the process of organizational development or can demolish the organizational progress.

This is another fact that as human resource proves to be nucleus of organizational resources, motivation is central and vital component which is key contributor in job satisfaction of an employee. Motivating employees has become one of the most significant and most demanding activities for the human resource management in any organization. There is no doubt that efficiency suffers with de motivated personnel.

Organizations invest in effectual strategies to get motivated workforce to compete in market. Salary alone does not prove to be vital motivator for everyone in an organization. Various factors motivate people differently depending upon the nature of an organization and its key contributors in developing learning environment.

Universities are a center of higher education where teachers play an important role in ensuring high quality of education by developing their students as global citizens for the outside corporate world. However, it is only possible when teachers in universities are motivated enough to accomplish their goals effectively. This research has elaborated various motivational factors that are influential to university teachers for their work effectiveness in enhancing their performance in order to increase the institutional effectiveness. This research is addressing the most unaddressed area of higher education system that is teachers' motivation. As according to Martin (2003) much of the research is available on student's motivation but a little on motivating teachers.

Higher Education Commission of Pakistan is putting its extreme efforts in polishing universities performance in Pakistan. HEC has taken various initiatives in order to improve teachers learning and development for higher education progress in the country.

These initiatives include national and international scholarships, teachers training, increasing salary packages, revising teaching compensation programs and much more. There is no doubt that intention behind these initiatives is to motivate teachers for enhanced performance in particular and to improve higher education standard in Pakistan as a whole.

Teachers are the building blocs of universities. Undoubtedly, teachers are the developers of positive and progressive society in any country. It is therefore, necessary to have highly motivated teachers particularly in universities where teachers' motivation is extremely demanded. The courage and dedication for developing high performance work systems can only be achieved if teachers would be willing to give their best.

However, in Pakistan motivation of higher education teachers by salary only is quite challenging for the government as it is difficult to compete with the private sector universities in compensation hence they must have to give attention to the non monetary factors such as recognition, feed back and opportunities for career development to retain their high quality 
teachers.

Famous rule of thumb in human resource management is that retaining employees is less costly than hiring new ones. When teachers in universities perform well, students are also high achievers and universities contribute more towards higher education.

Current research is an attempt to explore the motivational issues of university teachers in public sector of Pakistan and has elaborated the problems which prove to be hindering factors in achieving high teacher's motivation in universities.

A public sector university named as 'The Islamia University of Bahawalpur Pakistan' has been taken as case for this research in order to have in-depth investigation of different issues and their effect of teacher's motivation in public sector universities.

Jamia Islamia was established as a religious university in 1925 in Bahawalpur (Sub continent) whereas it was given a status of general university in 1975 and renamed as the Islamia University of Bahawalpur (Pakistan). Today there are 45 departments offering 74 disciplines. Including disciplines of Religious Affairs, Languages, Social and Basic Sciences; education is being imparted in the areas of Business Administration, Engineering, Agriculture, Veterinary Sciences, Computer, Law, Education, Fine Arts, Pharmacy, Life Sciences and Sports Sciences.

More than 12000 students are studying in its three main campuses, two sub campuses and different constituent colleges. Whereas about 500 teachers are teaching in permanent faculty as Professors, Associate Professors, Assistant Professors and Lecturers.

Following are set as the objectives of current study.

- To explore various issues of motivation for the teachers in higher education.

- To elaborate problems which are been faced by the teachers regarding these factors specifically in IUB.

- $\quad$ To suggest the recommendations with their implications.

\section{Literature Review}

Motivation is considered to be a soul achievement of human resources management practices as almost all the human resource practices has fundamental aim which includes job involvement and job satisfaction of an employee and acquiring high level of work motivation (Jerris, 1999).

Any organization cannot sustain without increased workers' motivation that is inevitable in the current scenario of hyper competition in corporate world. Robbins et al (2005) said that employee's motivation is the "willingness to exert high level of inspiration to reach organizational goals, conditioned by the efforts ability to satisfy some individual need". This definition clearly states that motivation is the willingness of employees to perform excellent work efficiently and this willingness only comes when they perceive that their effort would result in their need satisfaction. 
Employee's motivation can only be attained by realizing him/her that his individual needs or goals are aligned with organizational goals or achievement. Organizations need to extract various internal and external motivators for its workers so that they can increase their motivation in order to get long run success.

Nohria (2008) revealed in a recent study that motivation is measured by multidisciplinary indicators like engagement, satisfaction, commitment, and intention to quit. According to Rainey (2001) work motivation refers to the level of excitement, direction, and persistence of effort in work settings that a person tries to work hard and well.

Similarly, Dessler (1980) pointed out that "at the same time motivation is both one of the simplest and most complex job of management. It is simple because people are motivated by rewards. Therefore if you want to motivate someone you must have to find out what he or she wants and put that thing as a reward for him, as a result that person will be behaving in the desired way.

However, finding what your employee want and then alignment of individual and organizational needs can be complex at some stages. Motivating workers to implement elevated performance work systems is one of the basic aims of management principles that a successful business can have.

Although money is influential factor at every stage but at the same time it is not necessary that money alone can increase motivation of every worker there are intangibles (for instance empowerment, recognition and feedback) that are primary motivators for the workers inspiration to perform effectively (Fuhrmann, 2006).

\subsection{Teachers Motivation}

Identical to every organization, teacher's motivation in higher education institutions is one of the imperative and inevitable objectives of institution management. Teachers at higher education level play an important role in institution's success and its good will among students and academia. Again motivation is significant contributor in teachers' performance in delivering knowledge and grooming their students as the global citizens and master of their specialized field.

As Filak \& Sheldon, (2003) put their opinion that the motivation is crucial to the long term success and performance of any educational system. Similarly, Porter et al (1973) stressed that teacher's motivation is important for several different reasons. It is important for teachers self satisfaction and accomplishments, and for the reason that motivated teachers more probably work for educational reforms and progressive legislation particularly at higher education level and finally it is the motivated teacher who assures the completion of reforms that are originated at the educational policy making level. They further emphasized that teacher's job satisfaction and motivation is associated with decreased number of Institutional absenteeism and turnover.

Ololube (2004) explored the same point of view that increased motivation of teachers' leads to an increase in productivity that gives boost to the educational systems; hence the function 
of educations motivational methods cannot be underemphasized.

Different theories of motivation like Maslow's hierarchy of need theory, Herzberg's motivation hygiene theory and Adam's Equity theory are been stated in literature. These theories provide fundamental basis of motivation that help describing the motivation of employees in a systematic way and in understanding the contemporary theories of motivation like goal setting theory, reinforcement theory and expectancy theory etc.

Maslow's (1943) need-based theory of motivation is the most commonly known theory of motivation according to which there are five fundamental needs of a person i.e., physiological, security, affiliation, esteem, and self-actualization.

This theory can be true for teachers by understanding their physiological needs that may include pay, benefits, health and medical facility, accommodation and transportation, and comfortable working environment. A teacher' security needs are similar to any other employee who is always concerned about his/her job security, fair treatment, protection against threats and many more. Affiliation needs of a teacher can be the liking of head towards him, participation in departmental decisions, acceptance from colleagues and co-workers etc. whereas esteem needs of teachers may include the need for recognition from the departmental head, colleagues, subordinate, and students.

Similarly, Adams (1963) described motivation concept in terms of balance between employee's input and output. According to this theory if there will be a fair balance between the employees' inputs and outputs, employees will exhibit more work satisfaction, in the result of which motivated workforce will play effectual role in organizational development. Belief of this theory is that if employees feel that their inputs are greater than there outputs they will be de motivated in relation to their job and their employer.

The Adam's theory is well implemented in the field of higher education as the inputs that a teacher is expected to deliver can be hard work, empirical knowledge, tolerance, knowledge management, developing research oriented culture and enthusiasm to develop students etc and the outputs that he can expect from his employer to be provided can be salary, benefits, recognition, empowerment, appreciation and feedback etc.

The balance between both inputs which are being demanded by the institution and the outputs that are being formally or informally expected by the teacher from its institution is extremely necessary as any imbalance can create job dissatisfaction which can lead towards high job turnover. As Kyriacou et al (1979) stressed in their research that the reasons for leaving teaching profession may include lack of support from the departmental head, work overload, increased administrative task burden rather than engaging teachers in academic assignments.

On the other hand Herzberg (1959) has divided the motivational factors in terms of job satisfaction. He pointed out that factors giving job satisfaction (called motivators) are different from the factors that give job dissatisfaction (called hygiene factors).

He further emphasized that hygiene factors will not necessarily increase job satisfaction but can lead towards low motivation as compare to motivators. If we see teachers motivation in 
accordance with this theory, hygiene factors for a teacher in higher education can be the salary, support, interpersonal relationship with supervisors and work conditions.

If these factors are favorable in terms of highly facilitated working environment, increased colleague support and satisfactory compensation schemes, they can lead towards high work performance, however, if unfavorable these factors may directly influence teacher's inspiration/motivation to do his best.

On the contrary, Herzberg (1959) has described motivators as internal motivating factors which always stimulate the employee's motivation to put his best efforts. These motivators for teachers include recognition from departmental head, empowerment, students' achievement or career advancements.

As teachers play the mentoring role for their students, their primary motivation is associated with students learning achievement. The more students will grow and learn the more satisfaction of task achievement and job involvement would be increased among these mentors.

Further more viewing the previous literature on teachers' motivation, different authors have explored various issues of motivation for teachers in higher education institutions which can be valuable contribution in enhancing teacher's job satisfaction and involvement in particular and for organizational growth as whole.

As Adams et al (1989) highlighted in their study that student achievement can be a factor of motivation for teachers, i.e., if students are hardworking, talented and high achievers, teachers will be more motivated as a strong relationship between teacher satisfaction and student achievement not only will raise teacher's job satisfaction but also will prompt him to put his best.

Clarke et al (1995) have also found same relationship between student teachers relationship and have asserted that students can be more satisfying aspect for teachers than an administrative support. However, Bohlender et al (2001) stressed upon compensation as one of the important considerations in human resource management. They emphasized that it is a tangible reward to the employees for the services; therefore compensation must be in accordance to the need fulfillment of employees.

Along with compensation Fuhrman (2006) pointed out that job descriptions are important factors in motivating or de motivating employees. As unclear job description, stressful working environment, irrelevant administrative assignment can create overburden upon teachers and lead them to job dissatisfaction.

Similarly, as Davidson (2007) concluded in his research that high workload, large number of students in classes and burden of non teaching activities are the problems in creating a good job design for teachers in higher education institutions.

On the other hand Ofoeqbu (2004) established that a teacher needs different resources like technology (computers, projectors, multimedia and internet etc) and facilities (peons and financial aids etc) for effective classroom management and institution's improvement. 
Institution's support in providing class aids and academic resources can prove to be effectual motivators for teachers in order to have their extreme efforts.

Hughes (1991) in his research found professional growth as fundamental motivators for teachers. He further described that teacher's professional learning is a component of their career development that gives them effectiveness and satisfaction in teaching. (Hughes, 1991).

Likewise, Lynn (2002) supported the idea that educational leaders should provide professional learning and growth opportunities in order to motivate teachers and to enhance their performance.

Wright (1985) asserted that satisfaction of teachers is closely related to recognition. He further explains that teachers get motivation from the recognition of their achievements and accomplishments by their head, when they get appreciated for their valuable contribution or receive constructive feedback in order to correct their flaws. This open feedback and appreciation not only compel teachers to perform better but also allows the organization to grow collective manner.

As Memmott et al (2002) stresssed that organizations must provide feedback to its employees in order to create open communication environments in the organizations. Mufflin (1995) makes the same point describing that the lack of feedback leads to increased frustration in teachers and this disturbance impacts negatively on teachers performance.

Similarly, Photanan (2004) is of the opinion that training is one of the most important activities that can be used as a motivational program for employees' development. Training programs are one of those different input factors that give motivation to teachers' for their performance enhancement. (Woodward, 1992).

Hall et al (1997) examined in his research that autonomy is the most imperative factor of teacher's motivation.

They further added that teachers when given due authority or autonomy while designing their courses, class management and scheming evaluation mechanism, feel more confident and self-initiators as compare to those who are always instructed for the said tasks. The same as Praver et al (2008) found that teacher's empowerment is having academic freedom, i.e. planning lessons, formatting syllabus and selecting text books to recommend their students by their own and not by the department.

Moreover, Short et al (1994) found that teacher's empowerment is a process in which teachers develop the capability to grow and to resolve their problems. They explained that decision making, professional growth, status, self-efficacy, autonomy and impact are the six dimensions of teacher empowerment.

The above mentioned factors are giving a quick glimpse of major contributors of teacher's motivation. The major task of human resource management in universities or higher education institution is always centered to enhance the job satisfaction level, particularly of teachers as they are building blocks of institution as well as society at large. Current research 
has focused universities of Pakistan and has elaborated some of the major motivational factors that are directly affecting the teacher's performance at higher education level.

\section{Research Methodology}

This exploratory research supported by survey strategy was conducted to identify the issues of motivation for teachers in higher education of Pakistan. IUB was taken as case. In-depth interviews and questionnaires were used as key sources of collecting the primary data.

The sampling method used in this research was Stratified sampling. Three strata were selected as Dean, chairman/HOD and faculty. The sample size determined by the researchers was 100 with 1.29 margins of error and 99\% confidence level, belonging to all three strata explained above.

A comprehensive questionnaire consisting of 28 questions categorized in 8 major dimensions including space for suggestions was designed in order to get detailed insight of motivational issues in IUB. 100 valid questionnaires were analyzed in terms of percentages by using Microsoft excel.

The results of the questionnaire were discussed to identify which factors contribute the most towards motivating teachers and what are the problems regarding motivation of teachers at IUB.

In order to increase reliability of current research, in depth interviews have also been conducted from 33 teachers of the university belonging to all three strata and were included in discussion

\section{Findings and Discussion}

The survey was conducted in the three main campuses of the university that is Abbasia campus, Khawaja Farid campus and Baghdad ul Jaded campus. Profile of the respondents included: professors, assistant professors and lecturers who were working at Dean, Chairman/HOD and at faculty level.

Demographics of the respondents showed that $23 \%$ were $\mathrm{PhDs}$, $30 \%$ were post graduates (18 years education) and $47 \%$ graduates with (16 years education).

On the gender side $63 \%$ were male and $37 \%$ females. $61 \%$ of the sample represented young teachers with an age $20-30,23 \%$ were $30-40,11 \%$ belonged to $40-50$ and remaining $5 \%$ were more than 50 years old.

Their level of experience showed that $15 \%$ were newly recruited teachers with an experience less than one year, $22 \%$ had an experience of 1-2 years, 35\% had served between 2-5 years, $11 \%$ 5-10 years, $12 \%$ were of $10-20$ years experienced and experience of $5 \%$ respondents was more than 20 years.

On the management level major response was given by faculty side that was $79 \%$. Respondents who were serving as chairman or Head of the department were $19 \%$ and $2 \%$ were dean of a faculty. $18 \%$ of the respondents had the designation of professors, $25 \%$ 
assistant professors and $57 \%$ the lecturers.

On the income level 62\% respondents were newly appointed young teachers who were getting Rs20,000-30,000 from IUB, income of 10\% was between Rs.30,000--40,000, 13\% Rs40,000--50,000 and 15\% were getting more than Rs50, 000
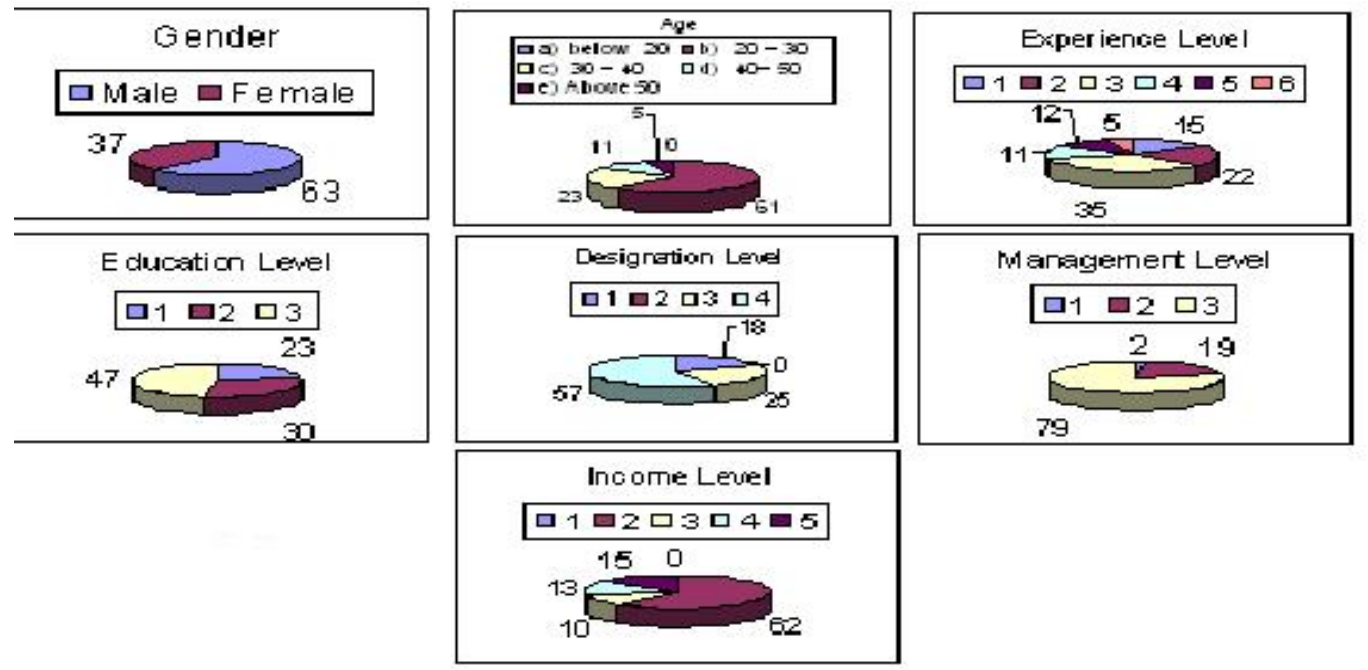

Fig ure 1. Demograp hics

Figure 1. Demographics of the survey respondents.

On exploring compensation as an issue motivation of teachers and measuring its role in motivating teachers of higher education, results show that compensation is a strong factor that motivates teachers in higher education specifically in the public sector universities like IUB where there are restrictions on salary increase.

Research reveals that teachers in IUB are not much satisfied with the current compensation and benefits packages. More than $50 \%$ of the respondents think that their salary is too low. Results show that $39 \%$ of the respondents disagreed with $21 \%$ strongly disagreed the statement that Overall the employee benefits (salary, allowances and part time lectures etc) meet their needs.

Similarly response on the statement that "compared to other universities in the country IUB has an excellent compensation and benefits package". More than $60 \%$ of the respondents were not satisfied at IUB when they compared their compensation package with the compensation packages of other universities particularly with the private sector in the country, as $41 \%$ disagreed and $25 \%$ strongly disagreed the statement.

It is also worth noting point here that people in the developing country like Pakistan, are more concerned about their financial constraints.

High salary or compensation benefits are encouraging factors for them, since it motivates them to put their best as they know the more they work, the more they will earn.

As one the Assistant Professor mentioned that

"Bonuses and compensation schemes can prove to be encouraging factor for university 
teachers as we all need financial support. We need to unwind this major responsibility in order to put our best in our profession”

However, on the other hand teachers also encouraged the HEC initiatives to improve salary and compensation schemes which are recently introduced. Research shows that $45 \%$ of the respondents agreed that new semester system has offered flexible pay packages which are encouraging factor for university teachers to improve their competence in order to have more financial security. One senior professor stressed that

"Now teaching job in universities of Pakistan is becoming more attractive due to latest initiative of higher education commission. It includes Tenure Track System which allows allocating high salary packages based on teacher's performance"

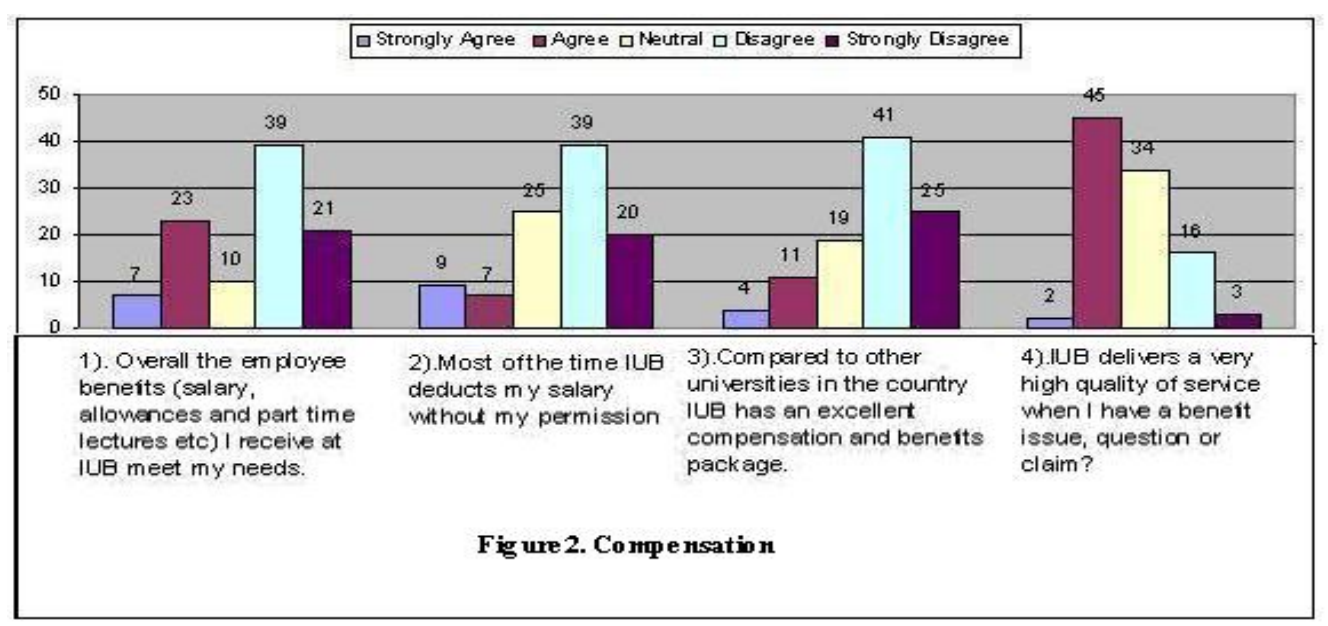

Figure 2. Response on questions related to Compensation.

Next issue assessed for the motivation of teachers is job design. Survey notifies that the major hurdle in job design at IUB is the amount of workload. Teachers have strongly expressed that current workload of 12 credit hours per week when combined together with other administrative activities (like examination, admissions, internships and disciplines) creates excessive workload on teachers.

More than $61 \%$ of the teachers demanded that workload must be reduced by decreasing number of credit hours per week and by involving non teaching staff into all the non teaching activities.

They stressed that if there will be less workload on teachers and less burden of non teaching activities; teachers will be more inclined towards research work. Results show that $61 \%$ disagreed the statement that workload is reasonable in IUB. However teachers seem to be satisfied with the number of students in each class and discipline of students at IUB as $62 \%$ agreed and $13 \%$ strongly agreed the statement that IUB enrolls a sufficient number of students in each class.

Similarly, $48 \%$ agreed and $12 \%$ strongly agreed the statement that students are respective and disciplined in IUB. However, Excessive workload and burden of non teaching activities is a hindering factor for university teachers as they think they can't carry research activities with 
full efficiency in presence of high workload and burden of non teaching activities.

As one of the Lecturers emphasized,

"When I am being asked to teach 12 credits hours per week plus extra classes. How can one expect me to put equal efforts for research as well? Our workload doesn't allow us to equalize our efforts in both (teaching and research) demanding fields"

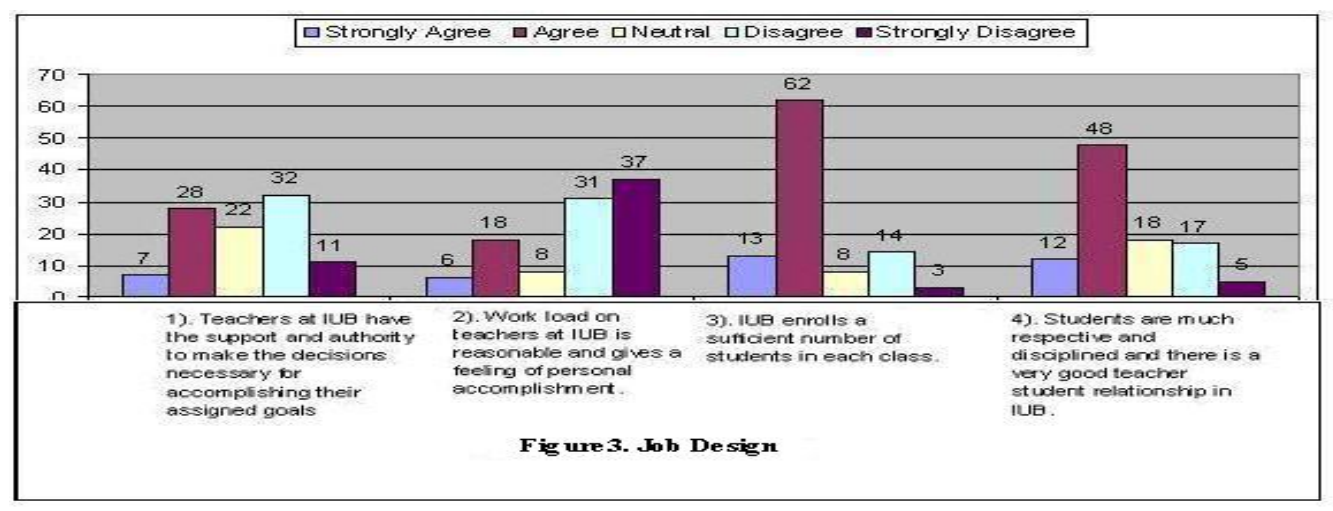

Figure 3. Response on questions related to Job Design.

Another issue is the work environment in order to elaborate its significance in motivating teacher to serve effectively in higher education. Interviews and questionnaire results shows that most of the respondents various departments of university were hesitant to give their opinion about the work environment.

Research results shows that $38 \%$ of the respondents showed concern about comprehensive support for accomplishing the tasks at IUB. Interview results when conducted for the purpose of exploring the issues, showed that teachers are having high level of teaching workload plus less numbers of professional growth opportunities.

As one of the lecturer stressed the point that,

"We teachers are facing strong communication gap among our faculty..... When I try to find someone to guide ..... I always return with empty hands"

Results showed that $67 \%$ of the respondents disagreed that they have formal mentor or guide for their teaching career. There is no doubt that all the teachers when inducted in university are not specialized in research and teaching. They feel the need of consistent training programs at different levels for their professional development.

Above mentioned interview statements and questionnaire results clearly shows that teachers in IUB feels sturdy need of mentoring and professional development culture as this is the important contributor in teachers' motivation. The main concern of every teacher is proper know-how of his/her work. The less guidance or improper training can lead to more job dissatisfaction which can results in high de motivation.

However, same issue is being differently viewed by senior professors and Deans of the university. They explored different initiatives taken from Higher Education Commission of 
Pakistan for faculty development in universities. They emphasized that yearly training programs are being held with collaboration of National Academy of Higher Education (NAHE) where university teachers are been given training on teaching and research methodologies.

As one of Deans of the University explored that,

"I am very optimistic regarding HEC initiatives.... Although they are not properly managed and synchronized yet they are important players in increasing teachers' motivation for establishing knowledge oriented culture in universities"

Other than communication teachers are satisfied with the resources available at IUB (personnel, finance and tools). Teachers have reported that IUB provides basic office working necessities such as separate work stations with computers and access to internet to each of its teacher and helps the teachers to conduct their designed activities like seminars and workshops for their students with financial and non financial support.

Results show that $44 \%$ of the respondents agreed and 16\% strongly agreed the question of resources available. Similarly teachers declared that they have no problem with the diverse background of their faculty fellows as 35\% agreed and 33\% strongly agreed the statement that IUB provides an environment where teachers from diverse background work together effectively and happily.

This section shows that environment at IUB for the teachers from diverse background and availability of resources for the teachers is a big strength of IUB. But there is some communication gap between the teachers and their supervisors like Chairman/HOD and Dean in some departments of the university as teachers of those departments were hesitant to answer about the behavior of and comprehensive support from their seniors.

As one of the senior professor pointed out that,

"There is no doubt that teachers are been motivated by number of factors ...... but still department politics and disturbed relationship with department head can lead a teacher towards frustrating situation ....... And sometime people start thinking to leave the university"

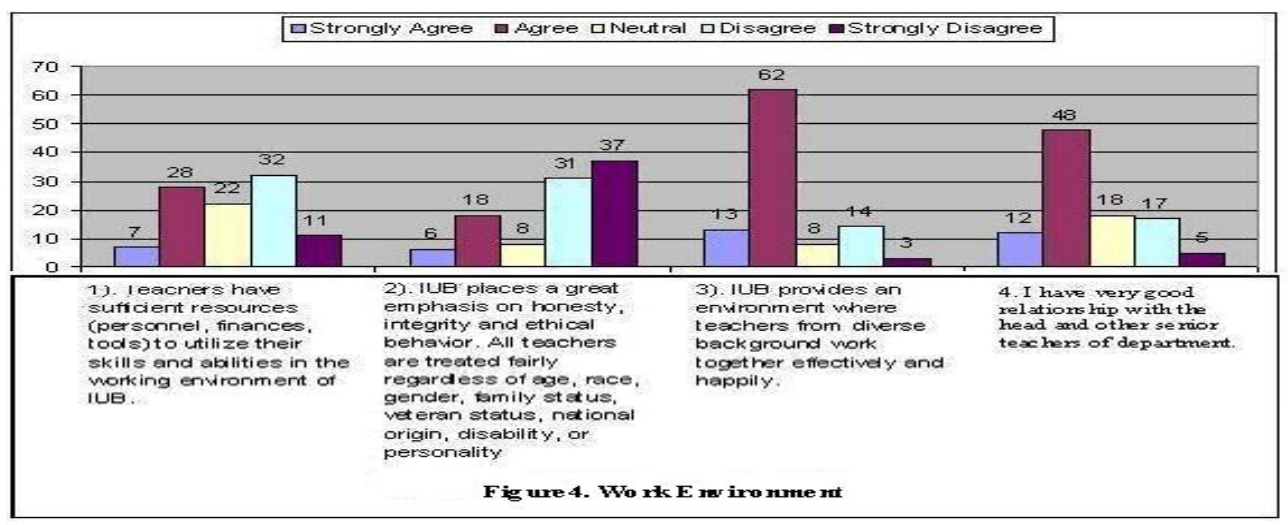

Figure 4. Response on questions related to Job Design. 


\section{Macrothink

Career development is the next issue which has been explored in the current research. Survey reveals that career development plays much important role in motivating teachers in higher education.

In the interview session teachers expressed their opinion that in the institutions of higher education teachers must always be given opportunities to grow. They expressed that teachers always want to improve their qualification.

Although IUB is providing quite good opportunities for career development of its teachers. FDP (faculty development program) where teachers are given scholarships and financial aids to go abroad and get higher qualification is of much importance and is one of the attractive factors for university teachers' motivation.

This is another initiative by HEC to allot full scholarships to teachers for their PHD studies. Results show that $78 \%$ of the respondents agreed that Faculty Development Program is highly motivating factor for university teachers. This attractive option does not only increase the motivation but compel the teachers to work hard and put their best in their profession.

As one Assistant Professor mentioned that,

"I can see the likelihood of my career development in this university..........as I have seen the people who have shown their work and proved themselves have been allocated scholarships....... I am highly motivated towards this professional development and working hard to achieve it"

However, detail interviews conducted in research with those teachers who were not of the view that FDP can increase motivation, revealed the opposite side of the picture. As it has been observed that $20 \%$ of the respondents were dissatisfied with this scholarship allocation program. They emphasized that IUB should take initiatives for those who can't leave their country due to personal problems.

As one of the teacher criticized that,

"I think overall impact of these scholarships is not much effective for the institution as in this way only one single person is been groomed and has enhanced his qualification. , there is no doubt that this money can be utilized in effectual manner if this same amount is been spent in staffing foreign faculty for conducting $\mathrm{PhD}$ and M .Phil programs inside the university"

This is another consequence of FDP that due to these scholarships IUB also is hiring young faculty to replace those who have gone abroad through FDP.

The performance of this young faculty, undoubtedly do not match with those experienced teachers who have availed the scholarships. 


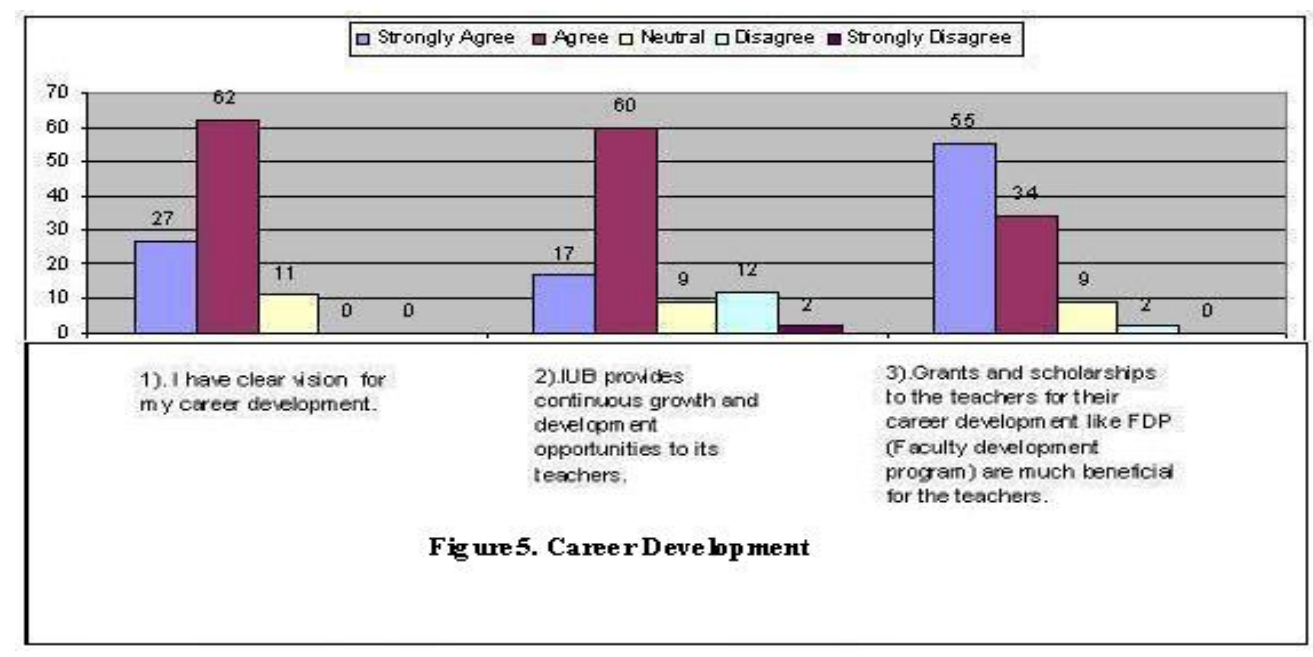

Figure 5. Response on questions related to Career Development.

Recognition and rewards is another issue of motivation of teachers in higher education. Questionnaire analysis and in depth interview results have shown that recognition for high performance proves to be an effective motivational factor for teachers in IUB. However, teachers didn't show their satisfaction regarding recognition and rewards initiatives in their university.

Results have shown that 57\% respondents disagreed the statement that they were recognized for their achievements. With the statement that, "recognition process is performance based in IUB”. Also, 51\% respondents disagreed and $10 \%$ strongly disagreed with the fairness and transparency of recognition process. Different issues when explored by the teachers during interview sessions were unfair treatment and preference to senior faculty members by departmental head as major hindering factors in transparent recognition and reward system.

As one of the junior lecturers expressed this problem emphasizing that,

"When duties would be assigned to junior lecturers and senior faculty will take credit of it. How can one have motivation in this scenario?".

Similarly, teachers stressed that there is traditional cultural perception that only senior faculty can perform batter and they should be allocated all the tasks and their respective rewards.

As one of the lecturers remarked that

"there is no learning by job rotation or by assigning diverse tasks to different faculty members so that they can learn while working on various positions. There is a special cabinet of department higher management who always takes decisions, being appreciated for it and secures respective rewards".

This is generally accepted that every employee in any organization needs appreciation or recognition for his performance.

As one of the lecturers at IUB stated that it is appreciation, not money every time which increases motivational level of employees. Similarly, respondents of this research seem to be 
seeking appreciation for significant work performance.

As one lecturer complained that,

"when a teacher gets good results he wants to be appreciated by university management, chairman or dean but in most of the cases it generally does not happen”. Another Assistant professor expressed that

"Teachers must be given monetary and non monetary incentives for their achievements like bonus salary, excellence awards or teacher of the year etc as when they will not be recognized for their achievements they will be less motivated to do that work"

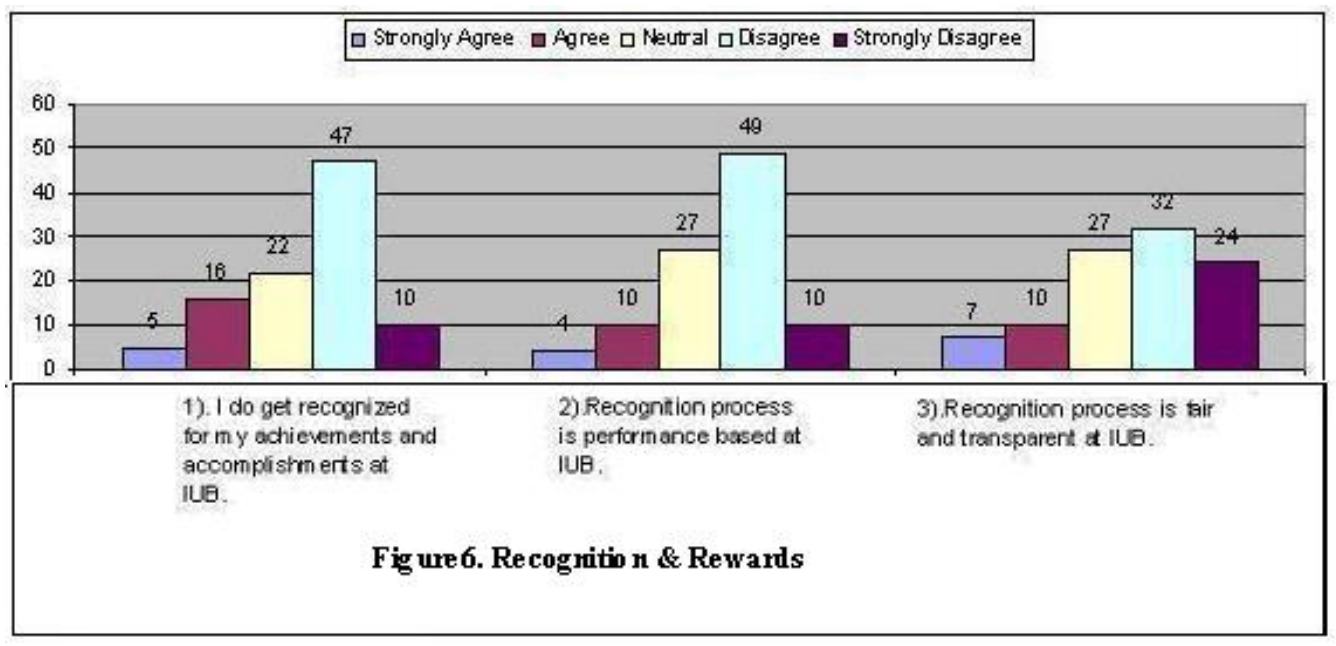

Figure 6. Response on questions related to Recognition \& Rewards.

Next issue examined in the study is feedback by departmental heads to their faculty members on working progress. There is no doubt that every successful organization maintains a proper performance management system which provides continuous feedback to its employees for their performance development and professional growth.

The Islamia University of Bahawalpur (IUB) has implemented traditional Annual Confidential Report (ACR) evaluation criteria. This report is been made by departmental head without any discussion with the teacher that what were his strengths and weaknesses.

Teachers showed their serious reservations on this system. They notified that feedback of the students about the teachers that is taken by university management is not provided to the teacher.

This is a bigger flaw of this program which eventually de motivate teachers for showing their high performance as good work should be appreciated at the time of its accomplishment and similarly mistakes should be corrected with immediate approach so that continuous professional growth could be made possible.

Moreover this feedback is only taken from the final classes whereas teachers need feedback of their students at each stage and they want to be recognized for positive feedback of the students and want to improve themselves if the feedback is negative somehow. 
As one of the senior professors explained that,

"This is true that students are the best evaluators of their teacher but this evaluation should be conducted after each semester from all the students so that teachers could be able to analyze their performance according to each subject".

Another concern of teachers in this regard is about comprehensiveness of performance evaluation criteria. As 36\% respondents disagreed and 18\% strongly disagreed with the comprehensiveness and transparency of performance evaluation system as it is been conducted by departmental head only.

Moreover, 37\% disagreed and 43\% strongly disagreed the statement that 360 degree feedback process is used as judgment tool in IUB. Content analysis show that nearly $68 \%$ of the respondents emphasized that evaluation data should be centralized to single authority that is chairman of the department. Teachers stressed that performance should be assessed by all the stakeholders like students, colleagues, subordinates, departmental head.

As one of the senior associate professor raised his concern that,

"How the chairman of certain department can evaluate any teacher's annual performance with single source of evaluation data which are students? Yes no doubt that they are major stakeholders but sometimes students proves to be poor evaluator when they do not put their minute attention while evaluating teacher's performance or when they dislike or like any specific teacher. This whole scenario leads to de motivation of teachers as they are not been evaluated on sufficient data”.

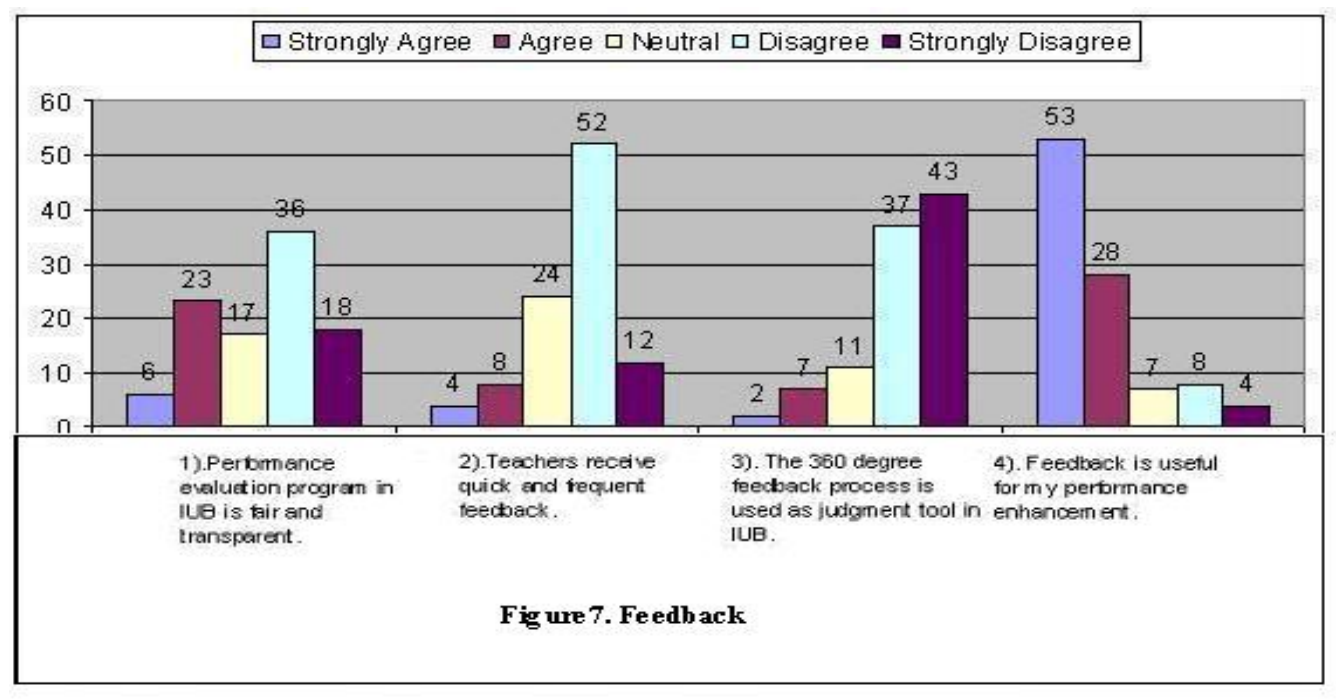

Figure 7. Response on questions related to Feedback.

Second last issue which has been proved as high motivational aspect is incessant training and workshops. Training is much more important for the growth and development of employees in any organization. It refreshes their knowledge and skills and gives motivation to work effectively with more courage and confidence.

During the interview session one of the assistant professor expressed his opinion, 
"Training is one of the major factors that gives motivation to the teachers in higher education as new knowledge emerges day by day and without proper training and skills, university teachers can feel inferiority while teaching".

Another teacher put his view that,

"Three months summer vacations can be properly utilized for teachers training. During this time different sessions of training and workshops can be organized with the help of experts and IUB teachers must be provided opportunities to visit other universities for learning so that they could refresh their knowledge and skills to teach effectively during the whole year"

A newly recruited lecturer demanded that,

IUB must complete its annual recruitment program for teachers in the month of June and then it must organize minimum two months training for them before assigning permanent courses to teach.

Results show that 32\% respondents strongly agreed and $41 \%$ agreed with the statement that Training \& workshop sessions organized for the teachers are effective for career enhancement. Likewise $48 \%$ respondents strongly agreed and $43 \%$ agreed the statement that Workshops and visits to other universities are useful for teacher's professional development.

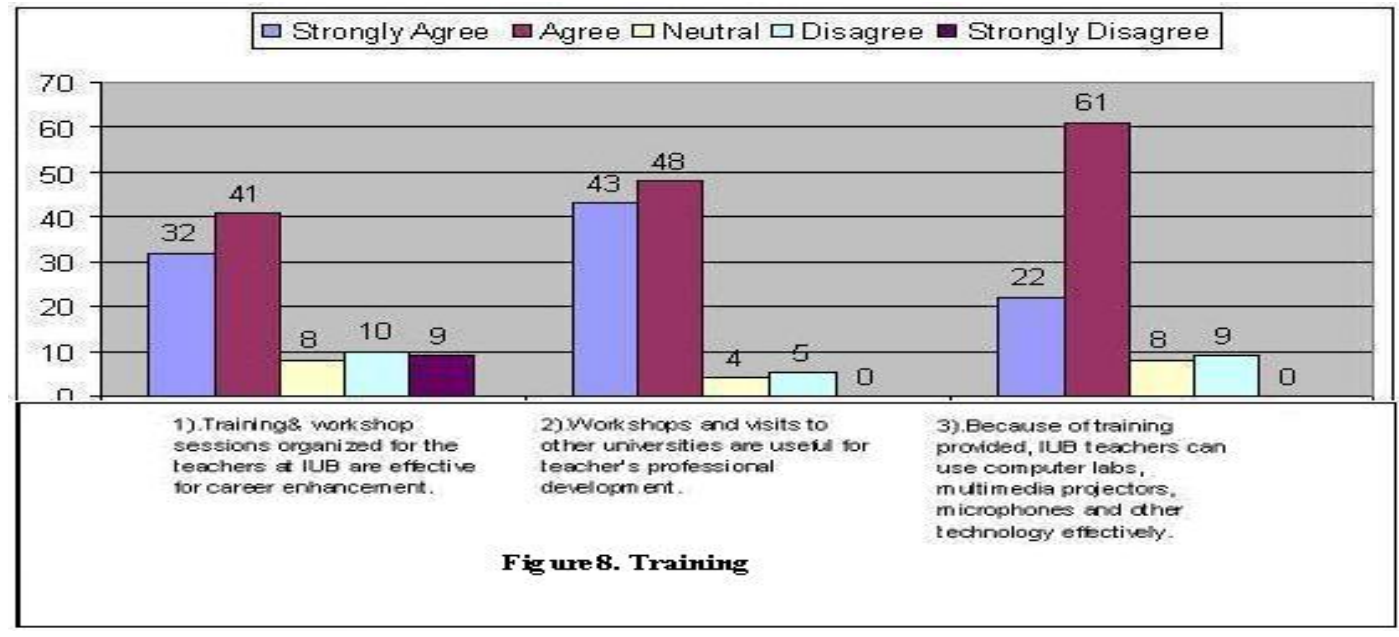

Figure 8. Response on questions Training.

The last but not the issue of motivation explored in this study is the empowerment and participation. It is one of the strongest factors of motivation for the teachers in higher education. Interviews with the teachers show that teachers want to be fully empowered in semester system environment to implement their own ways of teaching in classes. They want to design course outline for their subjects without the involvement of department head or chairman.

As one of the teachers put his point that,

"Some times I am given course outline by the department or certain topics to teach in the semester where in semester system environment teachers must be fully authorized to design 
their courses".

Further more teachers want to participate in departmental decision making not at operational level only but in policy making also as one of the assistant professor criticized that,

I am one of the most senior teachers in my department but I am not involved in all the decisions and policy making meetings of department. Chairman asks me to give opinion just for the operational level maters some times I feel I can better advise the department in some matter but my voice is not given proper weightage and when I see the failure of that policy I feel de motivated to teach in this department.

Results show that 36\% respondents were neutral, 32\% agreed and $16 \%$ disagreed the statement that teachers are involved in departmental decision making process. Researchers believe that this mix result are because of the fact that teachers participate in departmental decision making at operational level but not at all level like policy making. $63 \%$ of the respondents agreed with $10 \%$ strongly agreed the statement that teachers are empowered to improve their working practice in IUB.

Teacher's empowerment is a good situation at IUB it is a university's strength 43\% respondents think that their ideas are welcomed by the university management that is strength of IUB that university management must retain.

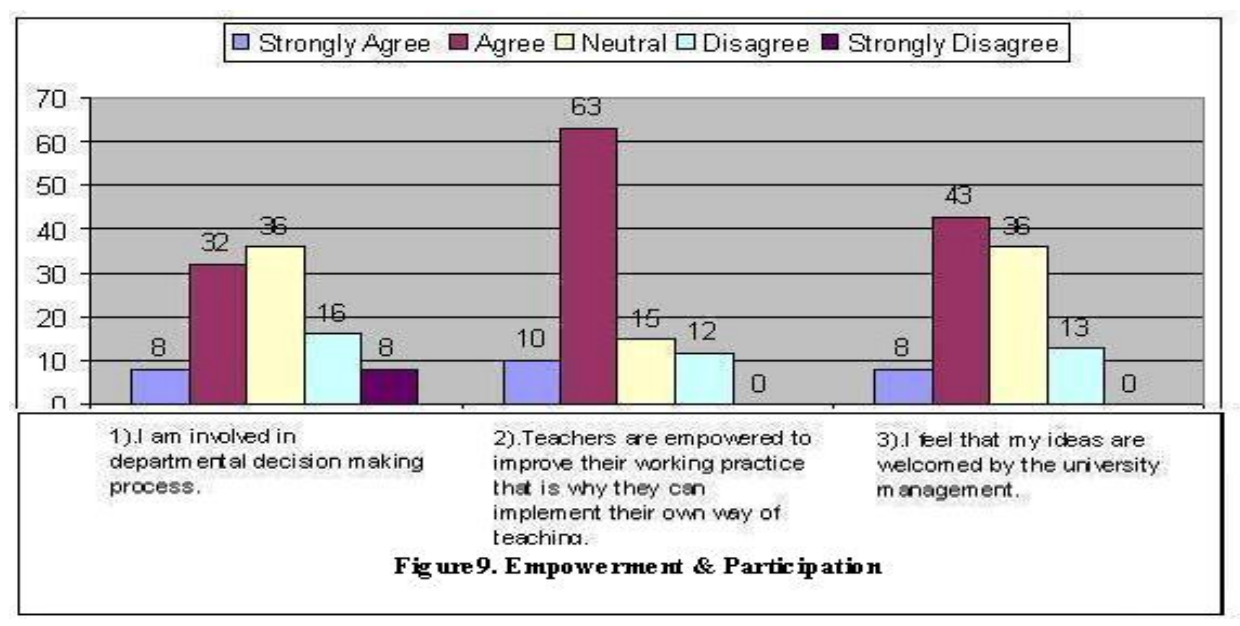

Figure 8. Response on questions Training.

\section{Suggestions and Recommendations}

On basis of the results researchers recommend that following measures must be taken by the university management.

1) Research results showed that teachers have shown their concern that although regular pay is received in time but overtime charges are provided much late and this delay of remuneration creates distress amongst the teachers and de motivated them.

If university management could minimize this delay of remuneration it would enhance the motivation level of teachers in the university. Financial system might be made faster in IUB 
in order to enhance its quality as survey has provided the evidence that teachers showed their reservations about the timely provision of remuneration against part time lectures and TA, /DA etc.

2) Teachers in IUB are not much aware of different benefits that they are receiving or they are entitled to receive for example insurance and health etc. Researchers have found that if teachers will be completely aware of all of these benefits they will be more motivated to teach effectively in IUB. Therefore let the teachers completely aware of all the benefits that they are entitled to receive.

3) Moreover, immediate attention in improving accommodation facilities is needed especially for newly recruited teachers as survey showed that IUB provides accommodation facilities to the limited number of teachers and newly appointed teachers face much problems regarding accommodation.

They are not provided accommodation by the university rather they have to arrange by their own,

A newly recruited female respondent pointed out that

"my home is much far from Bahawalpur city I can't come daily to Bahawalpur therefore I have got a private accommodation which is not much secure for me and it is a factor of de motivation for me to teach in IUB”.

Teachers have stressed this problem as they travel to and from the campus which increase their work stress as well as proves to be time wastage. If there would be proper accommodation facilities, teachers would be more motivated to put their quality time in teaching activities.

4) Another major problem in IUB for the teachers is the increased workload in the form of non-teaching activities like administration tasks. Teachers are of the view that all administrative activities must be carried out by non teaching staff.

Research showed that $67 \%$ of the respondents agreed that because of administrative tasks assigned to them, teachers cannot carry any research activity which is vital part for teacher's learning at higher education level. Therefore, effective department management program where teachers must be assigned to teaching and research activities and administrative activities assigned to administrative staff, might play an important role so that teachers feel satisfied that they are contributing knowledge by their research and teaching rather wasting their valued time in non academic activities.

5) Research results have shown that empowerment and recognition proves to be key motivators for teachers. However nearly $71 \%$ of the respondents mentioned that they are not recognized and awarded by their department

This is also a fact that in Pakistani universities departmental head posses significant powers in regard of his/her department. The departmental head can recognize the achievements of teachers by monetary and non monetary award for these awards could be monetary incentives, 
excellence awards, teacher of the year and public praise etc.

When head will be properly recognizing the achievements and accomplishments of their faculty members in their departments, there is no doubt that teachers will be more motivated to teach and they will be producing better results.

6) Survey showed although FDP is a good program to improve qualification of teachers but it can't serve all the teachers of the university due to its limitation also it could harm the quality of teaching in short run as senior teachers are leaving the university for three to five years.

Therefore it is recommended by the researchers that establish a centre of excellence within the premise of university where all the teachers' could improve their qualification and skills.

This center would be able to enhance the qualification and skills of all the teachers gradually and at the same time as teachers will not leave the university so quality of teaching will not be disturbed and it would definitely impact on the results of students also.

7) University has recently started performance evaluation program for the teachers. Research results explored that $66 \%$ of respondents are not satisfied with current evaluation system emphasizing that this program has many shortcomings as evaluation is taken only from the students of last semester and the results are not shown to the concerned teacher whose performance has been evaluated.

Moreover, this feedback of the students is not used for the promotion or demotion of any teacher. Whereas teachers need their evaluation from their students at each stage and want to be evaluated according to respective feedback. Improved evaluation system which incorporates 360 degree feedback, peer reviews and performance development plan can decrease the judgment errors and will be beneficial for teacher's professional development as well.

Performance evaluation is one of the major motivators for teachers. As nearly $70 \%$ of teachers agreed that performance evaluation system should be revised and should base on comprehensive performance evaluation mechanisms.

8) Teachers in higher education, undoubtedly, should have updated knowledge and subject expertise for effective teaching. Professional development training sessions and workshops are one of the major steps taken by Higher Education of Pakistan.

However, as it is on initial stage not all universities are getting complete benefits from these teachers training workshops. Research has shown that teachers are willing to increase their teaching and research expertise but there are a few efforts are being made at university level.

As 58\% of teachers disagreed that they are been provided by sufficient learning opportunities. Moreover, in interviews teachers also showed their concern about leaving the university only because they feel there is no effective talent management practices in university.

As one the assistant professor elaborated that

"I have been working here for last 6 years and I think now this university has nothing to give 
me as I am not having learning opportunities to increase my teaching and research capabilities."

\section{Conclusion.}

The primary goal of the study was to explore various issues of motivation for the teachers in higher education. Results of the study suggest although compensation and benefits package is a key motivator for the teachers but there are some other non monetary issues that affect teachers' motivation in higher education these include: job design, work environment, career development, recognition \& rewards, feedback, training, participation in decision making and empowerment.

Findings of the survey show that the role of supervisor (the chairman) is much important in retaining and motivating teachers in higher education unfortunately there is a communication gap between the chairmen and faculty teachers in some departments of IUB it must be eliminated. Therefore it is highly recommended on the basis of this survey to provide training to the chairmen to make them good administrators.

Workload of teachers in IUB i.e. 12 credit hours per week is much high along with other administrative activities it must be reduced to get good results in research and teaching. Teachers must be properly recognized for their achievements and feed back must be provided to them continuously and they must be given a sense of appreciation by involving them in departmental decision making.

\section{References}

Adams, B., \& Bailey, G. School is for teachers: Enhancing the school environment. NASSP Bulletin , 73, 44-48.

Adams, J. S. (1963). Towards understanding of Inequity. Journal of Abnormal and SocialPsychology , 67, $422-436$.

Bohlander, G., Snell, S., \& A, S. (2001). Managing Human Resources. South-Western College Publishing.

Clarke, R., \& Keating, W. F. (1995). A fresh look at teacher job satisfaction. ERIC Document Reproduction Service No. ED 391795.

Dessler, G. (1980). Human Behavior: Improving Performance at Work. Reston Publishing Company, Inc.

Euan, D. (2007). the pivotal role of teacher motivation in Tanzanian Education. the educational forum, kappa Delta pi, international honor society in education, Canada , 157-166.

Filak, V. F. (2003). Student Psychological Need Satisfaction and College Teacher-Course Evaluations. Educational Psychology , 23 (3), 235-247.

Fuhrmann, T. D. (2006). Motivating Employees. Advances in Diary Technology , 18, 93-101. 


\section{1) Macrothink}

Journal of Management Research ISSN 1941-899X 2010, Vol. 2, No. 2: E3

Hall, D., \& Bazerman, M. Organization design and job characteristics (In, J.L, Bess (Ed) teaching ed.).

Herzberg, F. M., \& Snyderman, B. (1959). The Motivation of Works. New York: John Wiley and Sons.

Jerris, A. L. (1999). Human Resource Management for Hospitality. New Jersy, USA,Upper Saddle River: Prentice-Hall, Inc.

Kyriacou, C., \& Sutcliffe, J. Teacher stress and satisfaction. Educational Research , 21, 89-96.

Lynn, S. (2002). the winding pathy:understanding the career cycle of teachers. the clearing house , 75, 179-182.

Martin. A.J. (2003).The student motivation scale: Further testing of an instrument that measures school students motivation. Australian Journal of Teachers Education,47, pp 88-106

Maslow, A. H. (1943). A theory of Human Motivation. 50, 370.

Max, P., \& William, O.-B. (2008). what motivates language teachers: investing work satisfaction and second language pedagogy. polyglossia , Volume 14,February, 2008 .

Memmott, L., \& Growers, S. ( March 12\& 13, 2002). retaining and motivating employees. washington tree fruit postharvest conference. washington: Yakima, WA,available at http://postharvest.tfrec.wsu.edu/PC2002G.pdf.

Mufflin. (1995). Manageent and Organization. New York, USA: South Western Publishing Company.

Nohria, N., Groysberg, B., \& Lee, L.-E. (2008). Employee Motivation: A Powerful New Model. Harvard Business Review , 1-8.

Ofoegbu, F. I. (2004). Teacher Motivation as an Essential Factor for Classroom Effectiveness and School Improvement. College Student Journal.Department of Educational Administration and Foundations, University of Benin, Benin City, Nigeria , 3 (1), 54-69.

Ololube, N. P. ( 2004). Professionalism: An Institutional Approach to Teachers' Job Effectiveness in Nigerian Schools. Seventh International LLinE Conference.

Photanan, T. (2004). Human Resource Focus. Bangkok: Innographics Ltd.

Porter, L., \& Steers, R. (1973). Organizational work and personal factors in employee turnover and absenteeism". Psychological Bulletin , 80, 76-151.

Rainey, H. (2001). Work motivation Handbook of organizational behavior. In $R$. T. Golembiewski (pp. 19-39). New York: Marcel Dekker.

ROBINNS, S. P., \& COULTER, M. Management (international edition no 7 ed.). Prentice Hall Inc. 
Short, P. M., Greer, J. T., \& Melvin, W. M. (1994). Creating empowered schools: Lessons in change. Journal of Educational Research , 32 (4), 38-52.

Woodward, T. (1992). Ways of training: Recipes for teacher training. Harlow: Longman.

Wright, M. D. (1985). Relationships among esteem, autonomy, job satisfactionand the intention to quit teaching of downstate Illinois industrial education teachers. University of Illinois, Urbana-Champaign,. Doctoral dissertation,Dissertation Abstracts International. 